Laporan Kasus

\title{
Pendekatan Transoral Sialolitektomi pada Sialolitiasis
}

Eko Wahyudi ${ }^{1}$, Novialdi ${ }^{2}$

\begin{abstract}
Abstrak
Pendahuluan: Sialolitiasis merupakan penyakit pada kelenjar liur yang ditandai dengan terbentuknya batu pada saluran atau kelenjar liur. Sering terjadi pada kelenjar. Mekanisme pembentukan batu masih belum diketahui dengan pasti. Gejala klinis yang paling sering dikeluhkan adalah bengkak dan nyeri saat dan setelah makan. Pemeriksaan penunjang yang dianggap sebagai baku standar untuk menegakkan diagnosis sialolitiasis adalah sialografi. Penatalaksanaan dari sialolitiasis bervariasi dan terus dikembangkan dari waktu ke waktu. Laporan Kasus: Dilaporkan satu kasus sialolitiasis submandibula kiri pada seorang anak perempuan umur 14 tahun yang dilakukan sialolitektomi dengan pendekatan transoral. Kesimpulan: Pada kasus diatas dilakukan sialolitektomi dengan pendekatan transoral, dimana teknik ini dilakukan pada kasus sialolitiasis yang berukuran besar dengan angka keberhasilan yang cukup tinggi dan angka kekambuhan yang rendah
\end{abstract}

Kata kunci: sialolitiasis, sialolitektomi, submandibula, transoral

\section{Abstract}

Introduction: Sialolithiasis are defined as salivary disorder which initiated by calculus formation in salivary duct or gland. Most commonly occurred on submandibular gland. Mechanism of calculi formation still remain unknown. Pain and swelling are the most clinical manifestation on sialolitiasis cases. Sialography claimed as the gold standard to confirmed it. Many techniques has developed for the last years to cure this disorder. Case Report: Reporting a left submandibular sialolithiasis case in a 14-years girl that treated by transoral sialolithectomy. Conclusion: In this case, we performed transoral sialolithectomy which has high success rate whereas low reccurency rate.

Keywords: sialolithiasis, sialolithectomy, submandibular, transoral

Affiliasi penulis : 1. PPDS THT-KL FK UNAND/ RSUP Dr. M. Djamil Padang, 2. Bagian THT-KL FK UNAND/RSUP Dr. M Djamil Padang Korespondensi: Eko Wahyudi (wahyudie@y7mail.com) Telp: +6281363854584

\section{PENDAHULUAN}

Sialolitiasis merupakan penyakit pada kelenjar ludah yang ditandai dengan terganggunya sekresi yang disebabkan oleh adanya obstruksi pada saluran kelenjar ludah dengan terbentuknya batu (calculi). Penyakit ini disertai dengan nyeri dan pembengkakan pada kelenjar, terutama setelah makan jika obstruksi yang terjadi belum seutuhnya, dan biasanya bersifat unilateral. Kasus ini lebih sering terjadi pada pria dibandingkan wanita dengan perbandingan 2:1. Sialolitiasis biasanya terjadi pada usia dekade 3 sampai dekade 6 , meskipun bisa terjadi pada usia remaja. ${ }^{1}$

Sialolitiasis lebih sering terjadi pada kelenjar submmandibula (85-90\%) dari jumlah kasus, dan bersifat unilateral, tanpa ada perbedaan sisi kiri dan kanan. Pada beberapa penelitian, rerata batu sialolitiasis di kelenjar submandibular berukuran 7,3 $\mathrm{mm}$. Sekitar $5-10 \%$ dari jumlah kasus sialolitiasis terjadi pada kelenjar parotis. ${ }^{2}$

Mekanisme terbentuknya batu sampai sekarang belum diketahui secara pasti akan tetapi diduga ada beberapa faktor yang berperan serta dalam terbentuknya batu diantaranya, inflamasi, iritasi lokal dan iregularitas pada saluran liur. Faktor ini yang diduga mempengaruhi terjadinya kalsifikasi pada materi organik yang terdapat pada saliva, sehingga terbentuk sialolith. Perbedaan yang mencolok antara kelenjar submandibular dan parotis adalah saluran dari kelenjar submandibular yang sudutnya lebih tajam dan mengarah keatas serta tipe sekresi yang bersifat lebih kental sedangkan kelenjar sublingual dan kelenjar ludah minor lainnya sangat jarang menjadi lokasi dari sialolitiasis (sekitar 0-5\%). ${ }^{3}$

\section{Anatomi Kelenjar Ludah}

Sistem kelenjar liur pada manusia secara garis besar terbagi atas dua kelompok besar, yakni kelenjar ludah mayor dan kelenjar ludah minor. Kelenjar liur mayor terbagi atas kelenjar parotis, kelenjar submandibular dan kelenjar sublingual. Sedangkan kelenjar liur minor terdiri atas kelenjar ludah yang tersebar pada mukosa saluran nafas dan cerna bagian atas. Kelenjar liur berfungsi untuk menghasilkan saliva, yang memegang peranan penting pada lubrikasi, pencernaan, imunitas, dan menjaga homeostasis pada tubuh manusia. 


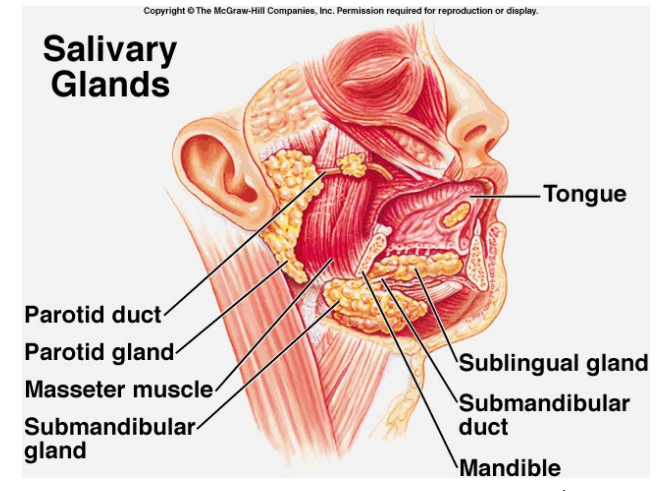

Gambar 1. Anatomi kelenjar liur ${ }^{1}$

Kelenjar berada di segitiga submandibula dimana bagian atas berbatasan dengan tepi bawah mandibula dan bagian bawah dibentuk oleh batas anterior dan posterior otot digastrikus. Selain itu, kelenjar getah bening submandibula, arteri dan vena fasialis, otot milohioid dan saraf lingualis, hipoglosus dan milohoid berada dalam segitiga submandibular ini. Duktus Wharton merupakan saluran utama dari kelenjar submandibula, dengan panjang kira $4-5 \mathrm{~cm} .^{1}$

\section{Diagnosis}

Diagnosis sialolitiasis dapat ditegakkan berdasarkan riwayat penyakit serta gejala klinis, pemeriksaan fisik dan bila perlu dilakukan pemeriksaan radiologi dan endoskopi

\section{Gejala klinis}

Pada beberapa kasus sialolitiasis, biasanya dapat bersifat asimptomatis. Gejala klinis yang paling sering ditemukan pada penderita sialolitiasis adalah nyeri dan pembengkakan pada sumandibula, meningkat terutama selama dan setelah makan. Nyeri tergantung dari obstruksi yang ditimbulkan dari batu yang terbentuk. Pada beberapa kasus, sialolitiasis menyebabkan stasis pada saliva, sehingga terjadinya kontaminasi bakteri pada kelenjar liur dan menyebabkan terjadinya sialoadenitis. Sedangkan pada kasus sialolitiasis yang tidak disertai infeksi pada kelenjar liur, akan terjadi atrofi dan penurunan fungsi sekeresi kelenjar yang disebabkan obstruksi jangka panjang pada saluran liur. ${ }^{4}$

\section{Pemeriksaan fisik}

Pada pemeriksaan fisik, biasanya ditemukan pembengkakan dan eritem pada daerah submandibula, postaurikula. Pada pemeriksaan intraoral ditemukan udem dan hiperemis pada muara saluran liur. Pada pemeriksaan bimanual, pemijatan pada saluran liur akan menyebabkan keluarnya sekret yang keputihan. ${ }^{5}$

\section{Pemeriksaan penunjang}

Pemeriksaaan penunjang yang dilakukan bisa bersifat radiologik dan endoskopik. Pada pemeriksaan radiologis dengan foto $X$-ray secara efektif bisa menunjukkan batu pada saluran liur, akan tetapi batu intraglandular dan batu yang berukuran kecil bisa terlewatkan. Menurut laporan Rauch dan Gorlin, hanya $20 \%$ dari sialolitiasis yang bersifat radiotransparan. Proyeksi $x$-ray yang biasa digunakan adalah proyeksi oklusal dan panoramik. 6,7

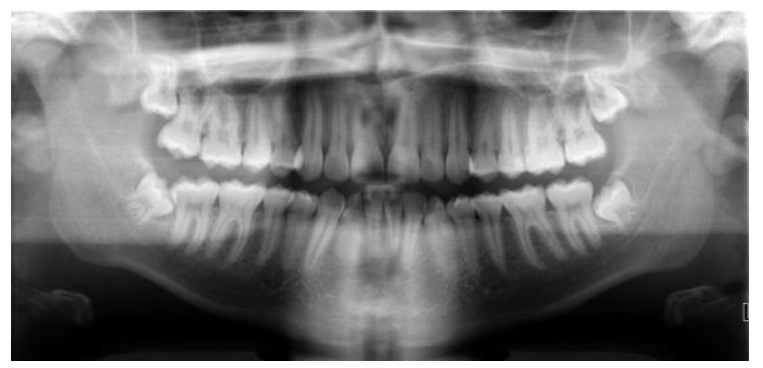

Gambar 2. Foto panoramik ${ }^{7}$

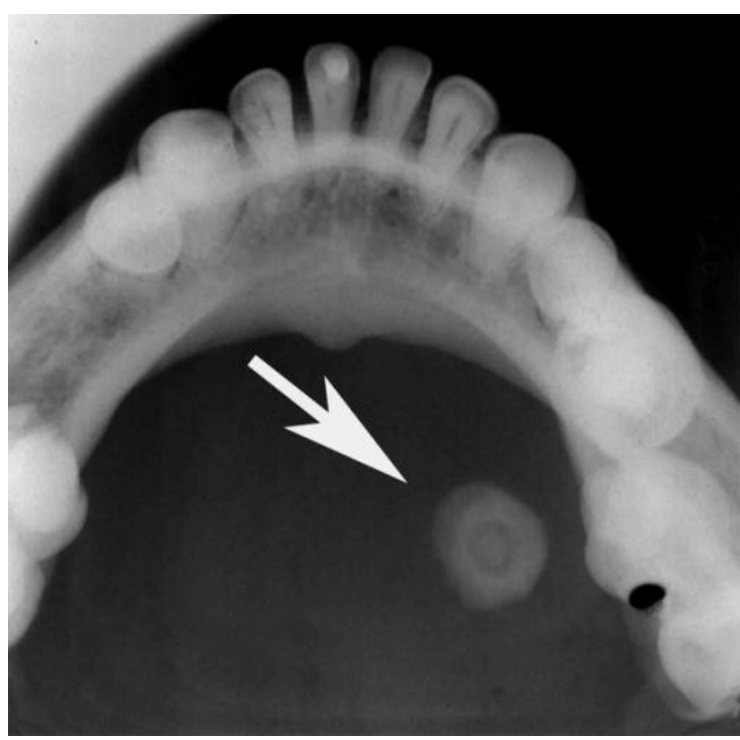

Gambar 3. Foto oklusal dengan adanya gambaran batu di mandibula ${ }^{7}$

Penggunaan Tomografi Komputer sangat membantu dalam mendiagnosis sialolitiasis. Selain itu, CT Scan juga bisa mendiagnosa dan menentukan lokasi batu dan kalsifikasi intraparenkim. Ultrasonografi juga bisa digunakan dalam menegakkan diagnosis sialolitiasis, walaupun tidak seakurat dibandingkan dengan CT Scan. ${ }^{7}$

Pemeriksaan penunjang pada kasus sialolitiasis yang bersifat endoskopik yang dikembangkan pada akhir2 ini adalah sialendoskopi. Selain bertujuan untuk diagnostik, sialendoskopi juga bisa bersifat terapeutik. Prosedur ini bersifat lebih aman, tidak terpapar radiasi dan bisa dilakukan pada poliklinik dengan pemberian anestesi lokal. ${ }^{6}$

\section{Komplikasi}

Komplikasi yang disebabkan pada sialolitiasis disebabkan karena adanya batu pada saluran yang akan menyebabkan terjadinya retensi saliva hingga terjadi infeksi pada jaringan parenkim pada kelenjar liur sehingga menyebabkan sialoadenitis. Selain itu juga bisa terjadi pelebaran lumen duktus dan striktur.

\section{Penatalaksanaan}

Penatalaksanaan pada kasus sialolitiasis 
telah berkembang sejak tahun 1960an, dan terus berkembang sampai dengan saat sekarang ini. Beberapa pilihan pada penatalaksanaan pada kasus sialolitiasis diantaranya adalah

\section{Pendekatan transoral}

Dilakukan pertama kali pada tahun 1968 oleh Seward, dengan melakukan operasi pada dasar mulut bagian anterior. Berbagai variasi dari teknik ini telah dikembangkan dari tahun ke tahun, dengan cara memperluas eksisi pada papilla sampai batu terlihat dan melakukan marsupialisasi hilus pada duktus setelah batu dikeluarkan. Angka keberhasilan teknik pendekatan transoral ini mencapai $82-98 \%$ dengan angka rekurensi $1-10 \%$ kasus. $^{8}$

\section{Sialografi intervensi}

Pada teknik ini, dilakukan ekstraksi secara blind pada batu pada kanalikulus dengan Dormia basket dan dikombinasikan dengan sialografi. Teknik ini mulai dikembangkan sejak tahun $1990 .^{9}$

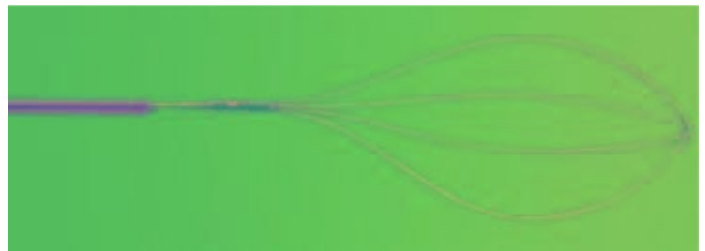

Gambar 4. Dormia Basket $^{9}$

\section{Sialoendoskopi terapeutik}

Diperkenalkan pertama kali pada awal 90an, dengan menggunakan endoskopi yang berukuran kecil dengan diameter 1,2-1,3mm. Setelah batu diketahui keberadaan nya dengan endoskopi, batu tersebut diambil dengan klem atau dipecahkan. Berbagai variasi juga dikombinasikan dengan teknik ini, dikarenakan kesulitan dalam memasuki ostium duktus, diantaranya dengan dilatasi dengan probe lakrimalis atau dengan kawat pemandu, papilotomi menggunakan laser $\mathrm{CO} 2$, sialolitotomi pada ostium duktus dan diseksi mikrosurgikal pada bagian anterior dari duktus. Kontraindikasi pada teknik ini adalah adanya obliterasi total pada bagian distal dari duktus tersebut. $^{8}$

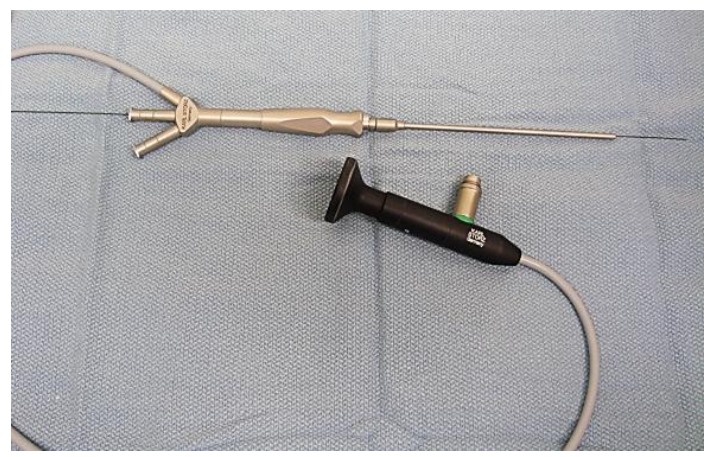

Gambar 5. Endoskopi yang dipasang kawat pemandu. ${ }^{8}$

\section{Extra Shock Wave Lithotripsy (ESWL)}

Teknik ini pertama kali diperkenalkan pada tahun 1989. Tujuan dari teknik ini adalah adalah untuk memecah batu sehingga berukuran tidak lebih dari $1,2 \mathrm{~mm}$. Pada teknik ini, dipandu dengan bantuan ultrasonografi. Oleh karena itu, teknik ini hanya bisa dilakukan pada batu yang berukuran $>2 \mathrm{~mm}$ atau lebih, sehingga bisa diidentifikasi oleh ultrasonografi. Kelemahan pada teknik ini adalah fragmentasi pada batu sering tidak sempurna, sehingga ada bagian pecahan batu yang tertinggal dan menjadi nidus dan menyebabkan sialolitihiasis yang berulang. ${ }^{8}$

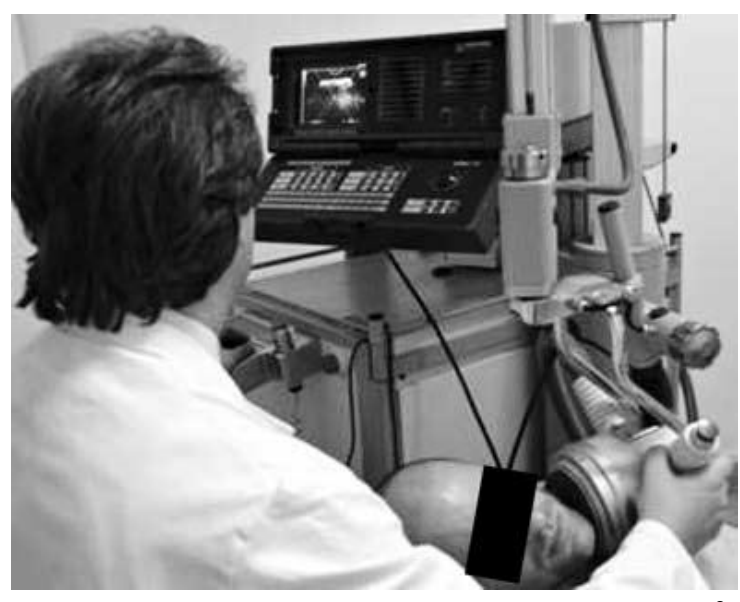

Gambar 6. ESWL dengan panduan ultrasonografi ${ }^{8}$

\section{Intaductal lithotripsy}

Teknik ini memiliki prinsip yang sama dengan ESWL, dimana dilakukan fragmentasi batu sehingga berukuran tidak lebih dari $1,2 \mathrm{~mm}$, akan tetapi dilakukan dengan memasukan probe ke dalam lumen duktus dengan bantuan endoskopi. Gelombang yang digunakan pada teknik ini biasanya berasal dari Laser, dan laser jenis Holmium merupakan yang paling sering digunakan. ${ }^{9,10}$

\section{LAPORAN KASUS}

Seorang pasien anak perempuan umur 14 tahun datang ke Poliklinik THT-KL dengan keluhan utama bengkak di bawah rahang kiri yang hilang timbul sejak 5 hari sebelum masuk Rumah Sakit. Bengkak dirasakan pasien segera setelah makan dan kemudian menghilang sekitar 20 menit kemudian. Nyeri dirasakan pasien di bawah rahang kiri sewaktu terjadi pembengkakan. Pasien tidak mengeluhkan nyeri sewaktu menelan. Pasien juga tidak mengeluhkan adanya gangguan kesulitan dalam proses menelan. Tidak terdapat keluhan suara serak pada pasien. Pasien tidak mengeluhkan sesak nafas jika terjadi pembengkakan dibawah rahang kiri. Tidak ada riwayat trauma pada leher sebelumnya. Tidak ada riwayat ketulangan pada pasien sebelumnya. Pasien masih bisa membuka mulut seperti biasa. Riwayat social ekonomi, pasien merupakan pelajar pada sekolah lanjutan tingkat pertama.

Pada pemeriksaan fisik pasien didapatkan keadaan umum sedang, komposmentis kooperatif, tekanan darah $100 / 60 \mathrm{mmHg}$, nadi $82 x /$ menit, nafas 22x/menit, afebris. Pemeriksaan telinga dekstra dan sinistra, liang telinga lapang, membran timpani utuh, reflek cahaya $(+)$. Pemeriksaan rinoskopi anterior pada 
kavum nasi dekstra dan sinistra, kavum nasi cukup lapang, konka inferior dan konka media eutrofi, sekret (-), septum deviasi (-) Pemeriksaan rinoskopi posterior, massa (-), PND (-). Pemeriksaan tenggorok arkus faring simetris, uvula ditengah, tonsil T1-T1 tenang, dinding posterior faring tenang. Pada regio submandibula kiri didapatkan pembengkakan, kenyal padat, tidak hiperemis dan tidak nyeri. Pada regio coli tidak terdapat pembesaran KGB

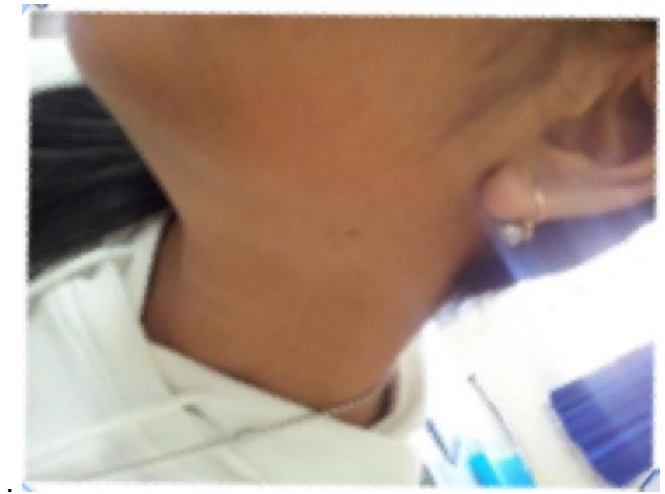

Gambar 7. Pembengkakan di bawah rahang kiri

Pada pasien ini, awalnya diduga dengan massa pada submandibula kiri, dan untuk menyingkirkan kemungkinan akan adanya dianjurkan untuk menjalani pemeriksaan CT Scan mandibula. Pada tanggal 30 April 2014 dilakukan CT Scan mandibula tanpa kontras, dengan hasil kelenjar submandibula kanan dan kelenjar parotis baik, tidak ada SOL, tidak ada kalsifikasi. Nasofaring dan orofaring baik. Kelenjar submandibular kiri tampak lebih besar, kalsifikasi tidak ada, SOL tidak ada. Tampak lesi hiperdens bulat ukuran $0,6 \mathrm{~cm} \times 0,5 \mathrm{~cm} \times$ $0,6 \mathrm{~cm}$ di region sublingual kiri proyeksi duktus Wharton distal. Didapatkan kesan suspek Sialodenitis kelenjar submandibula kiri dengan batu di proyeksi duktus Wharton kiri distal.

Pada tanggal 19 Juni 2014 dilakukan sialolitektomi pada pasien ini. Pasien tidur telentang dalam bius umum di atas meja operasi. Dilakukan prosedur aseptik dan antiseptik pada lapangan operasi. Dilakukan pemasangan Jennings gag pada mulut pasien sesuai ukuran mulut pasien. Dilakukan penyusuran duktus Wharton pada dasar lidah, dan dilakukan pengikatan di bagian bawah. Setelah muara duktus Wharton ditemukan, dilakukan pelebaran ostium duktus dengan klem kecil. Dilakukan irigasi spooling dengan Aquades murni ke dalam lumen duktus salivarius. Dimasukkan klem forsep ke dalam duktus hingga mencapi lokasi dari batu. Setelah batu bisa diraih, klem dikeluarkan pelan pelan. Setelah batu berhasil dikeluarkan, dilakukan prosedur penjahitan secara marsupialisasi dengan benang chromic 3.0. Jennings gag dibuka dan operasi selesai.

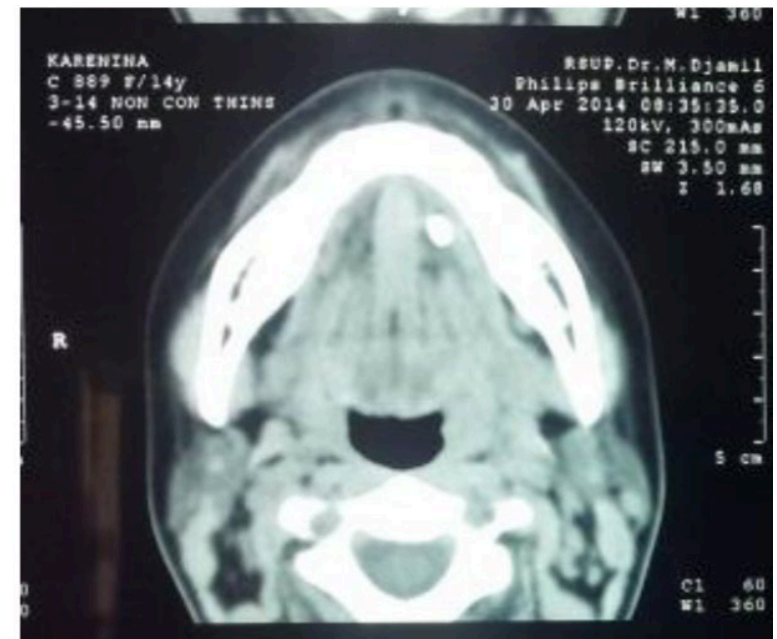

Gambar 8. Potongan axial CT Scan Mandibula

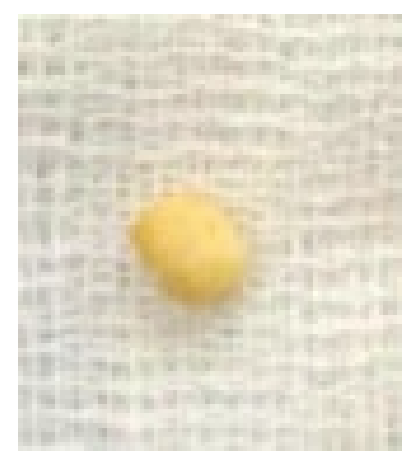

Gambar 9. Batu dari duktus Wharton

Instruksi pasca operasi: awasi tanda tanda vital, tekanan darah, nadi nafas dan suhu. Awasi tanda tanda perdarahan. Diet makanan cair bila bising usus (+) normal. Terapi yang diberikan injeksi antibiotik seftriaxon $1 \times 1 \mathrm{gr}$ (iv), injeksi deksametason $3 \times 5 \mathrm{mg}$ (iv), tramadol drip dalam IVFD RL ampul $50 \mathrm{mg}$ dalam RL 8 jam/kolf.

Post operasi hari pertama pasien merasakan nyeri di bawah dagu. Pasien juga terasa pusing dan tidak ada demam. Pasien masih merasa nyeri sewaktu makan makanan cair dan minum. Pada pemeriksaan status lokalis Telinga Hidung Tenggorok dalam batas normal. Pada rongga mulut, pada luka bekas operasi terdapat udem, hiperemis, clotting dan tidak ada darah mengalir., terapi diberikan antibiotik seftriaxon injeksi $1 \times 1 \mathrm{gr}$ iv, deksametason inj $3 \times 5 \mathrm{mg}$ iv dan asam mefenamat kapan perlu. Pada hari ke-2, pasien masih merasakan nyeri di bawah lidah tapi sudah agak berkurang. Pasien masih merasakan nyeri pada waktu minum. Demam tidak ada. Pusing tidak ada. Keluar air ludah bercampur darah tidak ada. Mual tidak ada, muntah tidak ada. Pada status lokalis Telinga Hidung Tenggrok dalam batas normal. Pada rongga mulut, masih terdapat udem pada bekas jahitan operasi, tapi sudah berkurang, hiperemis (+), clotting (-), luka operasi tenang. Terapi dilanjutkan dan pasien direncanakan pulang keesokan harinya.

Pada tanggal 22 Juni 2014 pasien dipulangkan dengan obat pulang sefixim 2x 100 dan Tinoridin $\mathrm{HCl} 3 \times 1$. Pasien dianjurkan untuk kontrol ke poliklinik THT-KL 3 hari kemudian pada tanggal 14 
Agustus 2014, didapatkan hasil laboratorium analisa batu dengan no. 22/LKK/BK- FK/2014, didapatkan hasil batu mengandung kalsium, fospat, urat dan kolesterin.

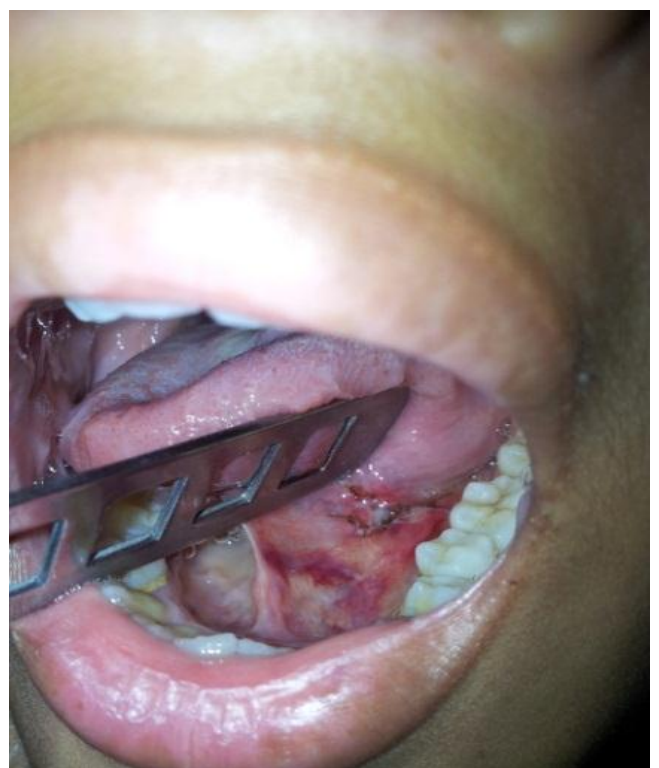

Gambar 11. Luka pasca operasi hari kedua

Pada tanggal 8 September 2014, pasien datang ke poliklinik THT-KL untuk kontrol post operasi. Pasien tidak ada mengeluhkan nyeri di bawah lidah pada waktu makan dan minum. Tidak ada bengkak di bagian leher. Tidak ada demam dan pusing. Pada pemeriksaaan fisik, status lokalis Telinga Hidung Tenggorok dalam batas normal. Pada rongga mulut, luka bekas operasi tampak tenang. Tidak ada tanda tanda infeksi. Pasien dipulangkan tanpa pemberian terapi medikamentosa dan disarankan untuk kontrol bila ada keluhan berulang

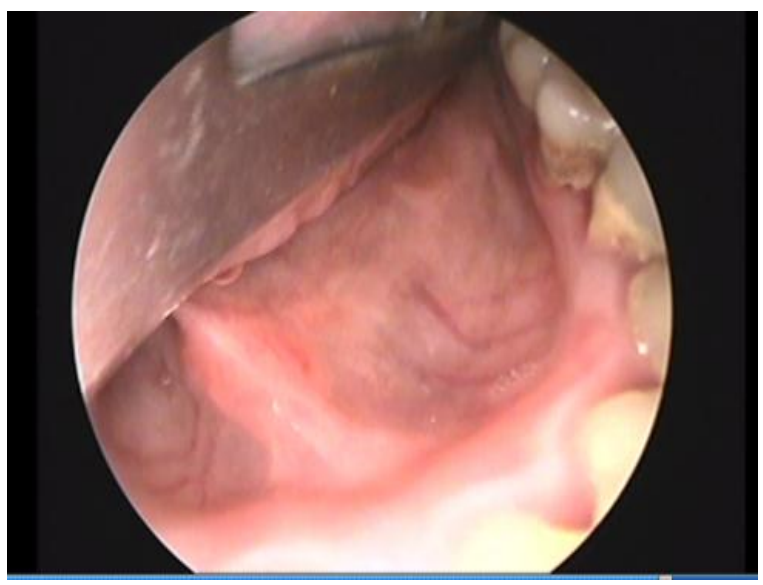

Gambar 11. Kontrol post op 8 september 2014

\section{PEMBAHASAN}

Telah dilaporkan satu kasus sialolitiasis submandibula kiri pada seorang anak perempuan umur 14 tahun yang didiagnosis berdasarkan gejala klinis, pemeriksaan fisik dan pemeriksaan penunjang. Pada kasus ini adanya riwayat bengkak di bawah rahang kiri yang disertai nyeri pada saat dan setelah makan, dan menghilang sendiri setelah sekitar 20 menit kemudian. Gejala klinis yang dialami pasien juga sesuai dengan kepustakaan seperti adanya pembengkakan yang hilang timbul terutama pada saat dan setelah makan, yang diikuti dengan nyeri pada bengkak tersebut. Pembengkakan disebabkan adanya aliran saliva yang terhambat oleh pembentukan batu pada saluran atau kelenjar liur. Keadaan ini lama lama bisa menyebabkan retensi saliva yang mengacu terjadinya infeksi dan terjadilah sialodenitis. Pada pasien pada pemeriksaan fisik ditemukan pembengkakan dibawah rahang kiri, tidak hiperemis. Hal ini sesuai dengan kepustakaan bahwa adanya pembengkakan di bawah leher dan adanya udem dan hiperemis pada muara saluran liur pada pemeriksaan intra oral. Pada pasien ini, awalnya diduga adanya massa pada daerah submandibular kiri. Oleh karena itu pada pasien ini dilakukan pemeriksaan CT Scan mandibula. Terlihat lesi hiperdens bulat ukuran $0,6 \mathrm{~cm}$ $x 0,5 \mathrm{~cm} \times 0,6 \mathrm{~cm}$ di region sublingual kiri proyeksi duktus Wharton distal pada CT Scan mandibula diikuti dengan adanya pembengkakan pada kelenjar submandibular kiri. Hal ini sesuai dengan kepustakaan bahwa CT Scan lebih efektif 10x lipat dibandingkan dengan rontgen dalam membedakan sialolitiasis, dimana juga bisa digunakan untuk mendeteksi abses atau adanya massa pada daerah itu.

Penatalaksanaan pada pasien ini adalah dengan melakukan sialolitektomi dengan pendekatan trans oral. Teknik ini memiliki angka keberhasilan yang cukup tinggi dalam mengeliminasi batu pada saluran atau kelenjar liur, sekitar $82-98 \%$, dan angka kekambuhan yang rendah, sekitar $1-10 \%$ kasus. Akhir akhir ini, teknik yang paling sering digunakan pada kasus sialolitiasis adalah sialoendoskopi diagnostik, dimana keberhasilannya cukup tinggi. Akan tetapi masih terkendala akan keterbatasan alat tersebut dan biaya yang masih mahal.

Terapi medikamentosa yang diberikan pada pasien ini adalah antibiotik, kortikosteroid, dan analgetik. Penggunaan seftriakson pada kasus ini sesuai dengan kepustakaan yang menganjurkan penggunaan antibiotik spektrum luas untuk mencegah terjadinya infeksi. Penggunaan kortikosteroid pada kasus ini bertujuan untuk mencegah terjadinya inflamasi dan udem pada mukosa rongga mulut pada bekas jahitan operasi.

Pada analisa laboratorium, didapatkan hasil bahwa batu dari saluran liur ini mengandung kalsium dan fospat. Hal ini sesuai menurut kepustakaan dimana batu pada saluran liur terdiri dari komponen yang terdapat pada saliva seperti kalsium, fospat, sitrat.

\section{SIMPULAN}

Sialolitiasis merupakan penyakit pada saluran dan kelenjar liur non-neoplasma yang paling sering terjadi. Gejala yang paling sering ditimbulkan adalah nyeri dan bengkak yang terjadi saat dan setelah makan. Sialografi merupakan pemeriksaan penunjang yang menjadi baku emas pada kasus sialolitiasis, disamping ada pemeriksaan penunjang lain yang 
sedang dikembangkan akhir akhir ini. Pada kasus ini, dilakukan pemeriksaan CT Scan mandibula menegakkan dikarenakan ketidaktersediaan pemeriksaan Sialografi.

Pada kasus ini, pendekatan sialolitektomi transoral digunakan karena secara statistik mempunyai angka keberhasilan yang tinggi. Komplikasi post operasi sialolitektomi transoral dapat berupa rasa kebas pada ujung lidah, pembengkakan pada dasar mulut, cedera saraf lingualis, ranula, dan infeksi.

\section{DAFTAR KEPUSTAKAAN}

1. Holsinger FC, Bui DT. Anatomy, Function and Evaluation of the Salivary Glands. In: Myers EN, Ferris RL, editors. Salivary Gland Disorder Otolaryngology. $15^{\text {th }}$ ed. Berlin: Springer; 2007. p.6-8.

2. Walvekar RR, Bowen MA. Nonneoplastic Diseases of the Salivary Glands. In: Johnson JT, Rossen CA. Baileys Head and Neck Surgery Otolaryngology, $5^{\text {th }}$ ed, Philadelphia: Lippinscot William \& Wilkins, a Wolters Kluwer business; 2014. p. 708-9

3. Lim HK, Kim SM, Kim MJ, Lee JH. Clinical, statistical and chemical study of sialolithiasis. Korean Association Oral Maxillofac Surg. 2012; 38:44-9

4. Panat SR, Aggarwal A, Upadhyay N, Kishore M, Alok A. Sialolithiasis: a case series, Journal of Dental Sci and Oral Rehab. 2013; 28-9.

5. Witt R, Edkins O. Sialolithiasis: Traditional \& Sialendoscopic Techniques. In Fagan J, editor. Open Access Atlas of Otolaryngology, Head \& Neck Operative Surgery. Cape Town: University of Cape Town; 2013.

6. Marshal F, Dulguerov P. Sialolithiasis Management, The State of Art. Arch Otolaryngol Head Neck Surg. 2003; 129:951-6.

7. Pagare SS, Krishnamurty V, Dua S. Submandibular sialolithiasis: A case report. Sci J 2008; 2:24-8.

8. Capaccio P. Modern management of obstructive salivary diseases, Acta Otorhinolaryngol ital, 2007;27(4):p161-72 .

9. Pastor-Ramos V, Cuervo-Diaz A, Aracill-Kesler L. Sialolitiasis, proposal for a new minimally invasive procedure: piezoelectric surgery. J Clin Exp Dent. 2014; 6(3):e295-8.

10. Kilinc $Y$, Cetiner S, Surgical Removal of a giant sialolith by diode Laser, Open Journal of Stomatology. 2014; 4:p484-8. 